\title{
Proses Pack Carburizing dengan Media Carburizer Alternatif Serbuk Arang Tongkol Jagung dan Serbuk Cangkang Kerang Mutiara
}

\author{
Sujita \\ Jurusan Teknik Mesin Fakultas Teknik Universitas Mataram \\ Jl. Majapahit 62 Mataram, Telp.0370 636087
}

\begin{abstract}
Abstrak
Tujuan dari penelitian ini adalah untuk mengetahui pengaruh penggunaan arang tongkol jagung dan serbuk cangkang kerang mutiara sebagai media carburizer pada proses pack carburizing terhadap sifa (struktur mikro) dan mekanis (uji kekerasan) baja karbon rendah. Bahan yang digunakan dalam penelitian ini adalah baja karbon rendah yang berbentuk selinder. Proses pembuatan spesimen dilakukan dengan pemotongan menjadi beberapa bagian, pemotongan dilakukan untuk memudahkan di dalam meletakan spesimen di dalam kotak karburisasi,kemudian serbuk arang kayu dan serbuk cangkang ditimbang sesuai dengan komposisi yang diinginkan dengan pencampuran serbuk cangkang kerang mutiara 5, 10 , 20 dan 25 (\% berat). Spesimen dilakukan perlakuan panas pada temperature $910^{\circ} \mathrm{C}, 930^{\circ} \mathrm{C}, 950^{\circ} \mathrm{C}$ dengan penahanan waktu selama 90, dan 150 menit. Kemudian dilakukan Uji kekerasan Vickers, pengujian foto struktur mikro dan uji komposisi. Dari penelitian ini dapat disimpulkan bahwa nilai kekerasan tertinggi rata-rata pada penambahan $20 \%$ serbuk cangkang di peroleh sebesar 262,47 kg/mm dan kekerasan material awal diperoleh sebesar 144,08 $\mathrm{kg} / \mathrm{mm}^{2}$. Dari hasil pengamatan struktur mikro dan uji komposisi diketahui bahwa terjadi pengerasan permukaan karena difusi karbon kedalam baja karbon randah.
\end{abstract}

Kata Kunci : Cangkang kerang mutiara, pack carburizing, uji kekerasan, uji komposisi, struktur mikro

\section{PENDAHULUAN}

Hasil alam Indonesia sangat melimpah, termasuk beberapa jenis hewan yang terdapat di dalamnya. Salah satunya adalah Kerang mutiara (Pearl) yang merupakan salah satu hewan jenis moluska. Hewan jenis ini paling sering dijumpai di daerah persawahan dan merupakan musuh petani karena dapat merusak tanaman padi. Untuk melindungi tanamannya, para petani berusaha untuk membasmi kerang mutiarasehingga tanaman petani dapat terhindar dari kerusakan. Ternyata kerang mutiarayang semula hanya merugikan para petani kini dapat dimanfaatkan karena cangkang kerang mutiaramengandung kalsium karbonat $\left(\mathrm{CaCO}_{3}\right)$ yang dapat dijadikan sebagai energizer alternatif di dalam proses karburisasi padat selain barium karbonat $\left(\mathrm{BaCO}_{3}\right)$.

Pada dasarnya bahan-bahan yang digunakan dalam karbonisasi yaitu, arang kayu, arang batok kelapa, dan arang kulit. Untuk mempercepat proses karbonasi maka di tambahkan barium karbonat $\left(\mathrm{CaCO}_{3}\right)$, natrium karbonat $\left(\mathrm{NaCO}_{3}\right)$ atau kalsium karbonat $\left(\mathrm{CaCO}_{3}\right)$. Ketiga bahan tambahan tersebut termasuk jenis bahan-bahan pembangkit tenaga dalam proses karburisasi. Karburisasi dilakukan dengan cara memanaskan bahan sampai 900 $950^{\circ} \mathrm{C}$ dalam lingkungan yang menyerahkan karbon, lalu dibiarkan beberapa waktu lamanya pada suhu tersebut dan kemudian didinginkan [1].
Simeon, dkk [2] mengadakan penelitian mengenai pengaruh proses carburizing terhadap sifat fisis dan mekanis sudu blower dinamo ampere pada mobil diesel didapatkan kesimpulan bahwa lama waktu penahanan (holding time) pada material ini mempengaruhi sifat mekanis material yaitu terhadap nilai kekerasan. Dimana material dasar tanpa perlakuan memiliki kekerasan rata-rata sebesar $664,1 \mathrm{~kg} / \mathrm{mm}^{2}$, material hasil quenching $850{ }^{\circ} \mathrm{C}$ dengan holding time 1 jam sebesar 723,64 $\mathrm{kg} / \mathrm{mm}^{2}$ dan material hasil quenching $850{ }^{\circ} \mathrm{C}$ dengan holding time 2 jam sebesar $730,5 \mathrm{~kg} / \mathrm{mm}^{2}$.

Jekti [3] menyelidiki proses pack carburizing pada mild steel dengan temperatur karburisasi $850^{\circ} \mathrm{C}, 900^{\circ} \mathrm{C}$ dan $950^{\circ} \mathrm{C}$, kemudian ditahan selama 15 menit dan 30 menit, lalu proses quenching dengan minyak dan tempering pada $550^{\circ} \mathrm{C}$. Hasil pengujian menunjukkan bahwa ketangguhan impact pada mild steel semakin berkurang dengan naiknya temperature karburisasi. Sedangkan kekakuan dari mild steel semakin meningkat akibat proses karburisasi, tetapi semakin turun dengan kenaikan temperatur karburisasi. Untuk kekerasan permukaan pada mild steel semakin berkurang dengan naiknya temperatur.

Tujuan dari penelitian ini adalah untuk mengetahui pengaruh penambahan serbuk cangkang kerang mutiarapada proses pack carburizing terhadap sifat fisis (struktur mikro) dan mekanis (uji kekerasan) baja karbon rendah setelah mengalami perlakuan. 


\section{Pack Carburizing}

Proses carburizing merupakan proses penambahan unsur karbon (C) ke dalam logam khususnya pada bagian permukaan bahan dimana unsur karbon ini didapat dari bahan-bahan yang mengandung karbon sehingga kekerasan logam dapat meningkat. Pengerasan permukaan pada logam dapat dilakukan dengan menambahkan unsur-unsur tertentu ke logam dasar tersebut seperti karbon, kalsium karbonat, nitrogen, dan yang lainnya. Untuk mempercepat proses maka ditambahkan barium karbonat $\left(\mathrm{BaCO}_{3}\right)$, kalsium karbonat $\left(\mathrm{CaCO}_{3}\right)$ atau natrium karbonat $\left(\mathrm{NaCO}_{3}\right)$ sebagai energizer yang bersama-sama material dimasukkan ke dalam kotak kedap udara untuk dipanaskan pada dapur pemanas pada temperatur carburing [6].

Pada pengarbonan padat dipakai arang yang dicampur dengan $10 \%-40 \% \mathrm{NaCO}_{3}, \mathrm{BaCO}_{3}$, baja dimasukkan ke dalam campuran ini, ditempatkan dalam suatu kotak dan ditutup rapat kemudian dipanaskan pada temperatur $850^{\circ} \mathrm{C}-950^{\circ} \mathrm{C}$ [4]. Setelah dilakukan holding time (waktu penahanan), proses dilanjutkan dengan pengerasan dengan quenching untuk mencapai kekerasan yang tinggi, dan tempering untuk menurunkan kegetasan dan tegangan sisa yang berlebihan.

\section{Kerang Mutiara}

Kerang mutiara (Pomacea canaliculata Lamarck) atau dikenal GAS (Golden Apple Snail). Kerang mutiaramerupakan salah satu jenis moluska. Keong ini berasal dari rawa-rawa di Amerika Selatan seperti Brazil, Suriname dan guatemala. Pertama kali, Kerang mutiara ini didatangkan dari Taiwan sekitar tahun 1980-an. Tahun 1981, hewan ini diintroduksi ke Yogyakarta sebagai fauna akuarium. Sekitar tahun 1985-1987, hewan ini menyebar dengan sangat cepat dan populer di Indonesia [3].

Kerang mutiaramuda berukuran 2-5 mm telah memakan alga dan bagian tanaman yang lunak. Pertumbuhan awal berlangsung selama 15-25 hari. Pada umur 26-59 hari, Kerang mutiarasangat rakus mengkonsumsi makanan, sedangkan setelah berumur 60 hari, Kerang mutiarasiap untuk berkembang biak. Kerang mutiara memerlukan sekitar 3-4 jam pada saat mengadakan perkawinan di daerah yang senantiasa mendapatkan air sepanjang tahun. Profil Kerang mutiaradapat dilihat pada Gambar 1 di bawah ini.

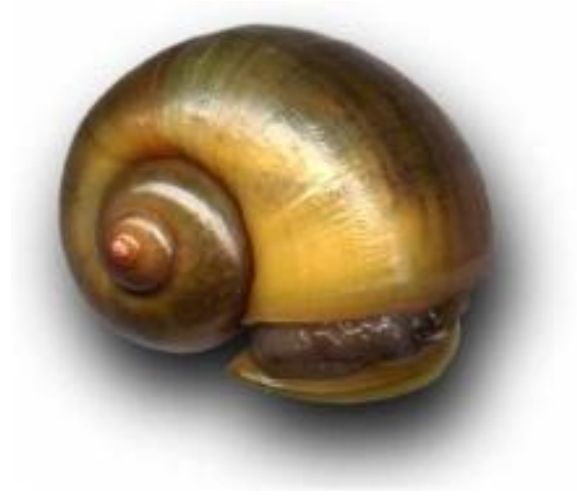

Gambar 1: Kerang Mutiara

\section{Pengujian Kekerasan}

Proses pengujian kekerasan dengan metoda Vickers mula-mula permukaan logam yang akan diuji ditekan dengan indentor berbentuk piramida intan yang dasarnya berbentuk bujur sangkar. Besar sudut antara permukaan-permukaan piramida yang berhadapan adalah sebesar $136^{\circ}$.

Angka kekerasan Vickers (VHN) merupakan angka kekuatan benda uji terhadap pembebanan pada tiap luas penampang bidang yang menerima pembebanan [5]. VHN dapat diperoleh dengan persamaan berikut:

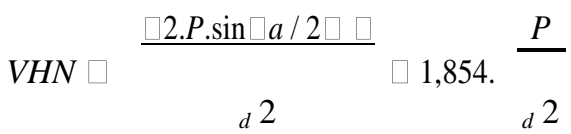

Dimana, $\mathrm{P}=$ Beban yang digunakan $(\mathrm{kg}) ; \alpha=$ Sudut puncak indentor $=136^{\circ}$ dan $\mathrm{d}=$ Panjang diagonal rata-rata $(\mathrm{mm})$.

Pengujian Vickers memiliki banyak keuntungan. Pengujian Vickers dapat dilakukan tidak hanya pada benda yang lunak akan tetapi juga dapat dilakukan pada bahan yang keras. Bekas penekanan yang kecil pada pengujian Vickers mengakibatkan kerusakan bahan percobaan relatif sedikit. Pada benda kerja yang tipis atau lapisan permukaan yang tipis dapat diukur dengan gaya yang relatif kecil.

\section{Pengujian Struktur Mikro}

Struktur bahan dalam orde kecil sering disebut struktur mikro. Struktur ini hanya dapat dilihat dengan menggunakan alat pengamat struktur mikro diantaranya : mikroskop electron, mikroskop field ion, mikroskop field emission, dan mikroskop sinar $-\mathrm{X}$.

Persiapan yang harus dilakukan sebelum mengamati struktur mikro adalah pemotongan spesimen, pengampelasan dan pemolesan dilanjutkan pengetsaan. Setelah permukaan spesimen rata betul kemudian dilanjutkan dengan proses pengampelasan dengan nomor kekasaran 
yang berurutan dari yang paling kasar (nomor kecil) sampai yang halus (nomor besar). Arah pengampelasan tiap tahap harus diubah, pengampelasan yang lama dan penuh kecermatan akan menghasilkan permukaan yang halus dan rata. Pemolesan dilakukan dengan autosol yaitu metal polish, bertujuan agar didapat permukaan yang rata dan halus tanpa goresan sehingga terlihat mengkilap seperti kaca. Kemudian mencelupkan spesimen dalam larutan etsa dengan posisi permukaan yang dietsa menghadap keatas. Selama pencelupan akan terjadi reaksi terhadap permukaan specimen sehingga larutan yang menyentuh spesimen harus segar/baru, oleh karena itu perlu digerak-gerakkan. Kemudian spesimen dicuci, dikeringkan dan dilihat atau difoto dengan mikroskop logam. Pemeriksaan struktur mikro memberikan informasi tentang bentuk struktur, ukuran dan banyaknya bagian struktur yang berbeda.

\section{METODOLOGI PENELITIAN}

\section{Alat dan Bahan}

Adapun alat-alat yang akan dipersiapkan sebelum melakukan penelitian ini adalah sebagai berikut Kotak karburisasi, tungku pemanas, Mesin polish, Mikroskop optik, Mesin uji kekerasan, Jangka sorong, Kamera, Tang penjepit, dan Amplas Sedangkan bahan yang akan digunakan adalah baja AISI 1018, arang kayu jati, serbuk cangkang Keong Emas, kertas gosok (dengan ukuran 80, 100, 400, 600, 800, dan 1000), dan Autosol

\section{Persiapan Spesimen}

Spesimen yang dipersiapkan sebanyak 93 buah, yang terdiri dari 3 spesimen awal tanpa karburasi, 90 spesimen dikarburisasi pada suhu $910^{\circ} \mathrm{C}, 930^{\circ} \mathrm{C}$ dan $950^{\circ} \mathrm{C}$ dengan waktu holding selama 90 menit dan 150 menit, dengan 5 variasi media karburizer dan 3 kali pengulangan ( 5 x 3 x 2 $\mathrm{x} 3)$.

Kotak terbuat dari baja karbon rendah dengan ketebalan $5 \mathrm{~mm}$ dengan ukuran panjang $500 \mathrm{~mm}$, lebar $100 \mathrm{~mm}$ dan tinggi $100 \mathrm{~mm}$, disekat menjadi 5 bagian (sesuai dengan komposisi media carburizer) benda-benda uji tersebut dimasukkan kedalam kotak karburisasi disusun seperti gambar dibawah ini dengan jarak tiap-tiap spesimen. Dimensi spesimen dapat dilihat pada Gambar 2 berikut ini:

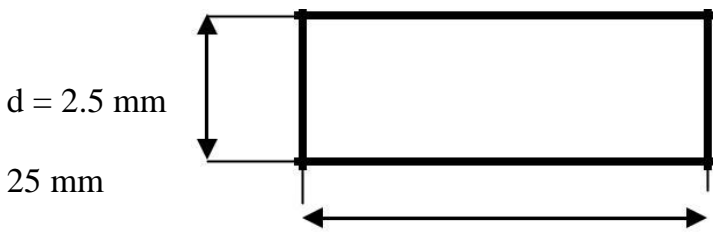

Gambar 2: Dimensi spesimen

\section{Persiapan Media Pack Carburizing}

Media pack carburizing yang digunakan dalam penelitian ini adalah medium padat, dengan komposisi yang sudah ditentukan dengan perbandingan $95 \%, 90 \%, 85 \%, 80 \%, 75 \%$ arang tongkol jagung dan $5 \%, 10 \%, 15 \%, 20 \%, 25 \%$ serbuk kerang mutiara yang ditumbuk sampai berukuran kira-kira 2 sampai $4 \mathrm{~mm}$ kemudian melakukan proses pengayakan sampai dengan ukuran 100 mesh dan ditimbang sesuai dengan komposisi diatas dan dicampur sampai rata.

\section{Proses Pack Carburizing}

Adapun tahapan proses pack carburizing adalah sebagai berikut:

1. Spesimen yang telah dipotong sebanyak 93 buah dan media arang kayu jati yang sudah dicampur dengan bahan energizer dimasukkan ke dalam kotak carburizing sampai berada di tengah-tengah kotak kemudian ditutup lagi lalu dimasukkan ke dalam tungku pemanas.

2. Kotak karburasi ditandai agar tidak tertukar pada waktu pemanasan.

3. Kemudian kotak tersebut dimasukkan ke dalam tungku dan pemanasan diatur dengan perlakuan pemanasan pada temperatur $910^{\circ} \mathrm{C}, 930^{\circ} \mathrm{C}, 950^{\circ} \mathrm{C}$, lama pemanasan 90, dan 150 menit

4. Setelah perlakuan tersebut di atas dilakukan maka kotak dikeluarkan dari dapur pemanas, kemudian kotak di buka dan spesimen dikeluarkan lalu dicelupkan ke dalam air.

5. Spesimen dibersihkan.

Spesimen yang telah melalui proses pack carburizing, selanjutnya dilakukan pengujian. Spesimen yang akan di uji di bersihkan dan diberi tanda sesuai dengan lama pemanasan dan jumlah berat serbuknya, kemudian dilakukan polishing.

\section{HASIL DAN PEMBAHASAN}

\section{Hasil Uji Kekerasan}

Pengujian kekerasan permukaan yang dipakai adalah metode Vickers dengan beban (P) sebesar 60 Kg. Pengujian ini dilakukan di Laboratorium Metalurgi Jurusan Teknik Mesin Fakultas Teknik Universitas Mataram. Data hasil uji kekerasan 
permukaan setelah proses pack carburizing dapat dilihat pada Tabel 1 berikut ini.

Adapun pengaruh konsentrasi serbuk cangkang Kerang mutiara dan waktu penahan terhadap nilai kekerasan dapat dilihat pada Gambar 1 sampai 3 di bawah ini.

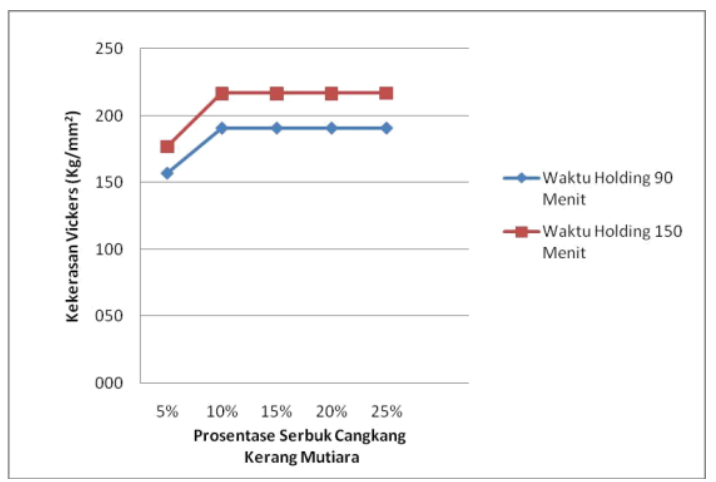

Gambar 1. Grafik Pengaruh Prosentase SCKM Terhadap Nilai Kekerasan Pada Suhu $910^{\circ} \mathrm{C}$

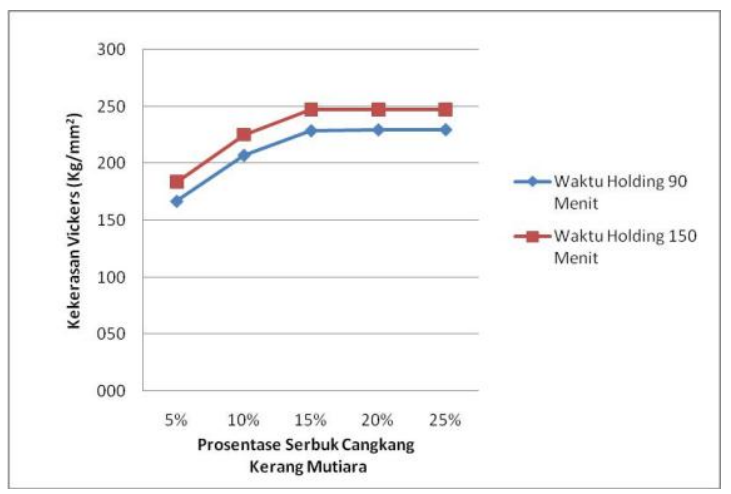

Gambar 2. Grafik Pengaruh Prosentase SCKM Terhadap Nilai Kekerasan Pada Suhu $930^{\circ} \mathrm{C}$

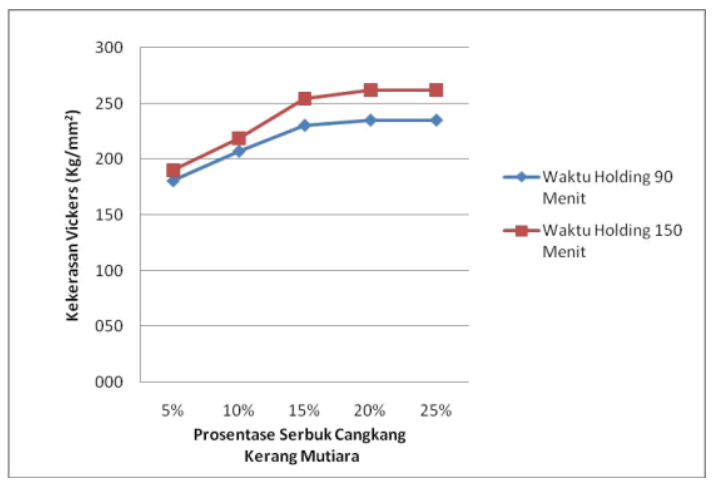

Gambar 3. Grafik Pengaruh Prosentase SCKM Terhadap Nilai Kekerasan Pada Suhu $950^{\circ} \mathrm{C}$
Dari Gambar 1 sampai Gambar 3 di atas menunjukkan bahwa pada spesimen material awal memiliki nilai kekerasan yang sangat rendah ini dikarenakan tidak adanya penambahan karbon pada material. Spesimen dengan waktu pemanasan 150 menit pada suhu $950^{\circ} \mathrm{C}$ memiliki nilai kekerasan paling tinggi $\left(262.27 \mathrm{Kg} / \mathrm{mm}^{2}\right)$ dibandingkan dengan proses lainnya dan matarial awal, dikarenakan adanya karbon aktif dan didukung oleh penambahan 20\% serbuk cangkang kerang mutiara sebagai energizer sehingga karbon lebih cepat berdifusi kedalam material.

Dalam proses ini jika serbuk cangkang kerang mutiara semakin banyak di imbangi dengan suhu holding yang lama maka karbon yang berdifusi ke baja akan semakin cepat dan membuat nilai kekerasan permukaan dari baja akan semakin besar, sehingga karbon akan lebih mudah berdifusi di antara celah-celah atom Fe. Pada proses carburizing dengan penambahan $20 \%$ serbuk cangkang dengan menggunakan pada suhu pemanasan $950^{\circ} \mathrm{C}$ dan waktu holding 150 menit diperoleh harga kekerasan tertinggi sebesar 262.27 $\mathrm{Kg} / \mathrm{mm}^{2}$ disusul dengan suhu pemanasan $930^{\circ} \mathrm{C}$, sebesar $247.06 \mathrm{~kg} / \mathrm{mm}^{2}$ dengan waktu penahanan 150 menit dan penambahan 20\% serbuk serbuk cangkang kerang mutiara, dan pada suhu pemanasan $910^{\circ} \mathrm{C}$ didadapatangka kekerasan $216.51 \mathrm{~kg} / \mathrm{mm}^{2}$, dan penambahan $15 \%$ serbuk cangkang kerang mutiara dengan waktu holding yang sama..

\section{Hasil Uji Struktur Mikro}

Hasil pengamatan struktur mikro dari material awal sebelum mengalami pack caburizing dapat dilihat pada Gambar 4 berikut ini:

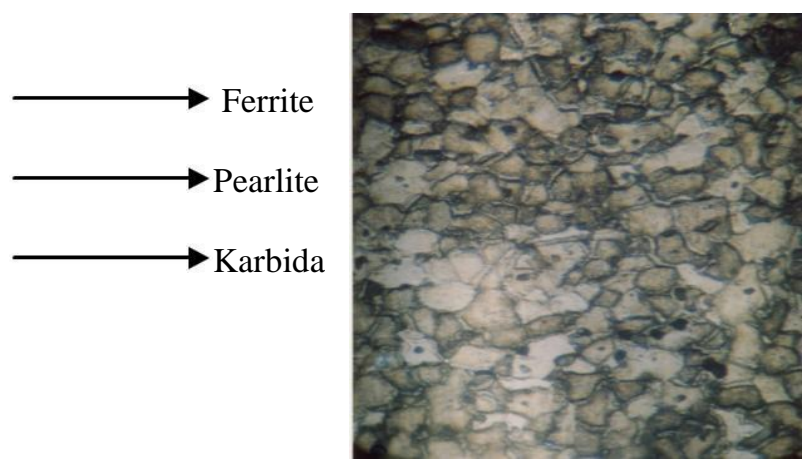

Gambar 4: Struktur Mikro material awal dengan pembesaran 400 kali

Dari Gambar 4 menunjukkan bahwa ferrite (berwarna terang dan putih) dan peralite (yang berwarna gelap dan hitam) lebih besar ukurannya dibandingkan dengan karbida. Karbida akan membesar jika terjadi perlakuan panas terhadap benda kerja (baja karbon rendah). Kemudian struktur ferrite lebih dominan dari pada struktur 
pearlite yang lebih sedikit jumlahnya, sehingga kekerasan dari material awal menjadi lebih rendah. Hal ini terjadi karena tidak adanya penambahan unsur karbon yang diberikan pada matrial awal dan sesuai dengan kandungan karbon yang terkandung pada material awal sebesar $0.159 \%$ C.

Hasil pengamatan struktur mikro dari material yang telah mengalami pack caburizing dengan perbandingan konsentrasi $85 \%$ arang kayu jati dan $15 \%$ serbuk cangkang kerang mutiara pada suhu $950^{\circ} \mathrm{C}$ dengan waktu carburizing 6 jam menggunakan media pendingin air tawar dapat dilihat pada Gambar 6 berikut ini.

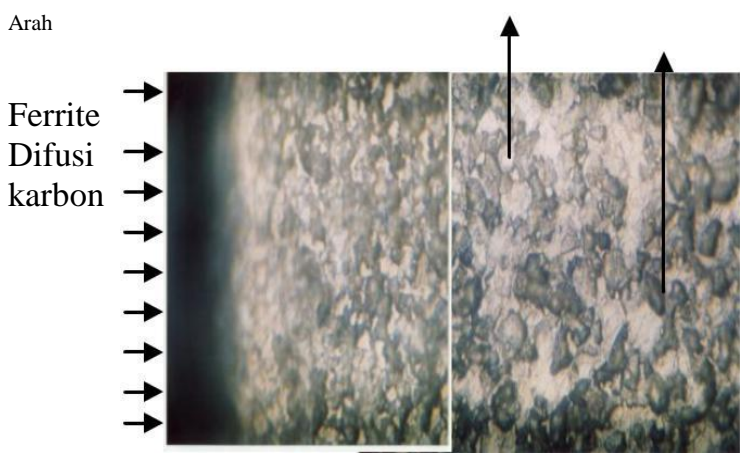

Gambar 5: Struktur mikro dengan pembesaran 400 kali.

Dari Gambar 5 menunjukkan bahwa strukturstruktur perlit jumlahnya semakin banyak dan ukuran butirannya mulai merata di sepanjang penetrasi walaupun pada sisi perlitnya masih terdapat banyak ferit. Peningkatan jumlah pearlite yang lebih banyak dibandingkan dengan struktur mikro material awal dapat terjadi karena adanya pengaruh penambahan unsur karbon ke dalam material selama proses difusi intertisi karbon dengan cara pemanasan pada material pada temperatur $950^{\circ} \mathrm{C}$ dengan lama waktu penahan 6 jam serta adanya penambahan serbuk cangkang kerang mutiaradengan konsentrasi $15 \%$ (\% berat) sebagai energizer yang merupakan unsur untuk mempercepat proses difusi karbon ke dalam baja sehingga dapat membentuk struktur pearlit lebih banyak. Sehingga menjadikan spesimen ini menjadi lebih keras dari sebelumnya dan juga di pengaruhi oleh terjadinya proses pendinginan yang cepat sehingga dapat merubah sifat fisis dari pada baja.

Hasil pengamatan struktur mikro dari material yang telah mengalami pack caburizing dengan perbandingan konsentrasi $90 \%$ arang tongkol jagung dan $10 \%$ serbuk cangkang kerang mutiara pada suhu $950^{\circ} \mathrm{C}$ dengan waktu carburizing 150 menit dapat dilihat pada Gambar 6 berikut ini.

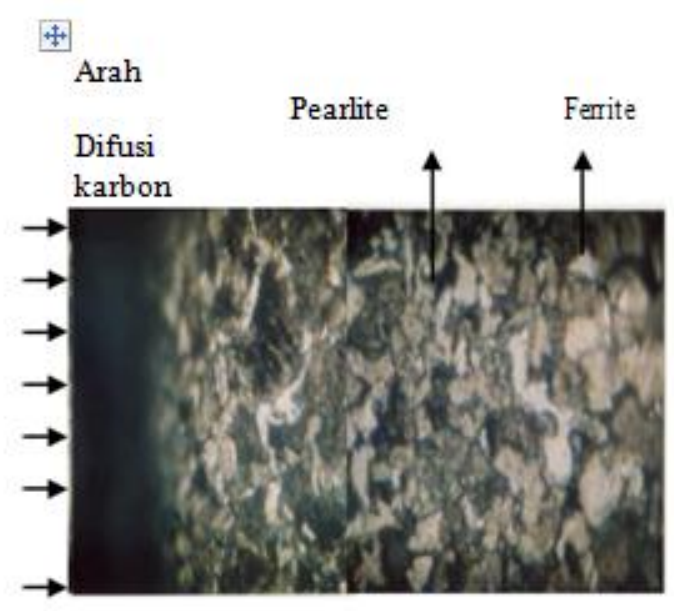

Gambar 6: Struktur mikro dengan pembesaran 400 Pearlite kali.

Dari Gambar 6 menunjukkan bahwa peningkatan jumah perlit yang paling banyak dibandingkan dengan struktur mikro yang lain, selai itu penetrasi dari karbon juga cukup dalam dan butiran-butiran pada perlit ukurannya lebih besar dibandingkan dengan konsentrasi sebelumnya. Dengan ukuran butir yang lebih besar maka kekerasan yang dihasilkan juga akan lebih besar. Ini terjadi karena adanya perbandingan bahan tambahan yang berupa $90 \%$ arang tongkol jagung dan $10 \%$ serbuk cangkang kerang mutiara sebagai energizer yang merupakan bahan pembangkit tenaga dalam proses karburisasi, serta didukung dengan proses quenching menggunakan media pendingin larutan garam. Hal ini dapat meningkatkan jumlah karbon yang cukup banyak, sehinga pada saat pemanasan berlangsung difusi karbon ke dalam baja menjadi lebih cepat sehingga dapat merubah butir struktur mikro dan nilai kekerasan yang lebih keras di bandingkan dengan material uji sebelumnya .

\section{Hasil Uji Komposisi}

Tabel 1: Hasil Uji komposisi kimia sebelum perlakuan (Raw Material) dan sesudah perlakuan (carburizing) dengan variasi $15 \%$ serbuk cangkang kerang mutiara dengan waktu penahanan 150 menit dan suhu pemanasan $950^{\circ} \mathrm{C}$. 


\begin{tabular}{|c|c|c|c|}
\hline No & Nama Unsur & $\begin{array}{c}\text { Sebelum } \\
\text { Perlakuan } \\
\text { Rata-rata } \\
(\%)\end{array}$ & $\begin{array}{c}\text { Sesudah Perlakuan } \\
\text { Rata-rata } \\
(\%)\end{array}$ \\
\hline 1 & $\mathrm{Fe}$ & 98.11 & 92.91 \\
\hline 2 & $\mathrm{C}$ & 0.159 & 0.78 \\
\hline 3 & $\mathrm{Mn}$ & 0.624 & 0.70 \\
\hline 4 & $\mathrm{Cr}$ & 0.110 & 1.29 \\
\hline 5 & $\mathrm{Mo}$ & 0.078 & 0.47 \\
\hline 6 & $\mathrm{Cu}$ & 0.241 & 0.34 \\
\hline 7 & $\mathrm{Nb}$ & 0.016 & 0.03 \\
\hline 8 & $\mathrm{Ti}$ & 0.008 & 0.80 \\
\hline
\end{tabular}

Dari data pada Tabel 2 di atas, hasil uji komposisi pada spesimen sebelum dan setelah perlakuan, terjadi adanya peningkatan kadar karbon dimana spesimen sebelum perlakuan (raw materials) mengandung $0.159 \% \mathrm{C}$ sedangkan setelah perlakuan (carburizing) pada bagian permukaan menurut uji komposisi mengandung $0.78 \%$ C. Hal ini membuktikan bahwa karbon telah masuk ke bagian permukaan baja karbon rendah.

\section{KESIMPULAN}

Dari hasil pengujian dan pembahasan dapat disimpulkan bahwa:

1. Variasi komposisi media karburizer dan penambahan serbuk cangkang kerang mutiara berpengaruh terhadapa nilai kekerasan baja karbon rendah.

2. Keefektifan penambahan serbuk kerang mutiara tergantung pada suhu pemanasan. Penambahan $20 \%$ serbuk kerang mutiara (SKM) akan berpengaruh terhadap kenaikkan angka kekerasan pada pemanasan pada suhu $950^{\circ} \mathrm{C}$. Pada suhu pemanasan $910^{\circ} \mathrm{C}$ dan $930^{\circ} \mathrm{C}$, penambahan $20 \%$ (SKM), kenaikkan nilai kekerasan pemukaan cenderung stagnan. Demikian pula untuk proesentase $15 \%$ dan $10 \%$ (SKM) Nilai kekerasan rata-rata akan mengalami stagnan pada suhu pemanasan $910^{\circ} \mathrm{C}$ dan $930^{\circ} \mathrm{C}$

3. Waktu holding berpengaruh terhadap kenaikkan angka kekerasan spesiment.

4. Angka kekerasan tertinggi sebesara 262.47 $\mathrm{Kg} / \mathrm{mm}^{2}$ didapatkan pada suhu pemanasan $950^{\circ} \mathrm{C}$, waktu holding 150 dengan variasi media carburizer $80 \%$ arang tongkol jagung dan 20\% SKM.

5. Dari pengamatan foto struktur mikro pada material awal terdapat struktur ferrite yang lebih banyak di bandingkan dengan foto struktur mikro setelah perlakuan (carburizing). Sebaliknya jumlah pearlite setelah perlakuan (carburizing) menjadi lebih banyak dibanding material sebelumnya.

\section{DAFTAR PUSTAKA}

[1] Amanto, H. \& Daryanto, 1999. Ilmu Bahan, Bumi Aksara, Jakarta Arifin, 1977. Ilmu Logam, Ghalia Indonesia, Jakarta

[2] Fata O. A., Simeon A. I., Isiaka., Oluwole O., and Joseph O. B., 2010. Pack Carburization of Mild Steel, using Pulverized Bone as Carburizer: Optimizing Process Parameters, Leonardo Electronic Journal of Practices and Technologies, ISSN 1583-1078, issue 16, p. 1-12

[3] Jekti, 1990. Diktat Biologi 1, Fakultas Peternakan, Unram, Mataram.

[4] Fisis dan Mekanis Sudu Blower Dinamo Ampere pada Mobil Diesel, Tugas Akhir, Universitas Muhammadiyah Surakarta

[5] Koswara, Engkos. 1999. Pengujian Bahan Logam, Humaniora Utama Press, Bandung. Setiyawan, A., 2003. Penelitian Mengenai Pengaruh Proses Carburizing Terhadap Sifat

[6] Suherman, W. 1987. Pengetahuan Bahan, FTI - ITS, Surabaya. Surdia,Tata, dan Saito, S. 2000. Pengetahuan Bahan Teknik cetakan kelima 